OPEN ACCESS

Edited by: Federica Scarpina, University of Turin, Italy

Reviewed by:

Gerjo Kok,

Maastricht University, Netherlands

Natalia Piana,

Healthy Lifestyle Institute Perugia, Italy

*Correspondence:

Guendalina Graffigna guendalina.graffigna@unicatt.it

Specialty section:

This article was submitted to Psychology for Clinical Settings,

a section of the journal

Frontiers in Psychology

Received: 30 June 2016 Accepted: 02 September 2016 Published: 16 September 2016

Citation:

Menichetti J and Graffigna G (2016) "PHE in Action": Development and Modeling of an Intervention to Improve

Patient Engagement among Older Adults. Front. Psychol. 7:1405 doi: 10.3389/fpsyg.2016.01405

\section{"PHE in Action": Development and Modeling of an Intervention to Improve Patient Engagement among Older Adults}

\author{
Julia Menichetti and Guendalina Graffigna * \\ Department of Psychology, Catholic University of the Sacred Heart, Milan, Italy
}

The increasing prevalence of chronic conditions among older adults constitutes a major public health problem. Thus, changes in lifestyles are required to prevent secondary conditions and sustain good care practices. While patient engagement received great attention in the last years as key strategy to solve this issue, to date no interventions exist to sustain the engagement of older chronic patients toward their health management. This study describes the design, development, and optimization of PHEinAction, a theoretically-driven intervention program to increase patient engagement in older chronic populations and consequently to foster healthy changes that can help reduce risks of health problems. The development process followed the UK Medical Research Council's (MRC) guidelines and involved selecting the theoretical base for the intervention, identifying the relevant evidence-based literature, and conducting exploratory research to qualitatively evaluate program's feasibility, acceptability, and comprehension. The result was a user-endorsed intervention designed to improve older patients' engagement in health management based on the theoretical framework of the Patient Health Engagement (PHE) model. The intervention program, which emerged from this process, consisted of 2 monthly face-to-face 1 -h sessions delivered by a trained facilitator and one brief telephonic consultation, and aimed to facilitate a range of changes for patient engagement (e.g., motivation to change, health information seeking and use, emotional adjustment, health behaviors planning). PHEinAction is the first example of a theoretically-based patient engagement intervention designed for older chronic targets. The intervention program is based on psychological theory and evidence; it facilitates emotional, psychological, and behavioral processes to support patient engagement and lifestyle change and maintenance. It provides estimates of the extent to which it could help high-risk groups engage in effective health management and informs future trials.

Keywords: patient engagement, intervention development, older patients, chronic disease, patient activation

\section{INTRODUCTION}

Aging of the population is a major health challenge and a considerable concern for public health authorities and institutions (Ebrahim, 1997; Lutz et al., 2008). Older adults are likely to suffer from chronic diseases (Denton and Spencer, 2010), they often have multiple unmet health needs (Wolff et al., 2002; Chatterji et al., 2015), and they often have limited access to personal and contextual 
resources needed to purposeful engage in accomplishing health goals (Shearer et al., 2009). It is difficult for health services to meet those needs, because of the lack of resources. Consequently, renewed models of care where patients are involved as main partners of their health management are needed (Anderson and Funnell, 2005; Thomson et al., 2005). Indeed, it is becoming ever more important for patients to be partners in care, not simply recipients of care as in older paradigms, because the actions people do-as well as do not-are critical for successful disease prevention and management (Mosen et al., 2007). The existing evidences suggest that patients who are partners in care have the potential to improve health outcomes through the adoption of health-enhancing behaviors and the reduction of health inequities (Coulter, 2005, 2012; Hibbard and Cunningham, 2008; Jordan et al., 2008; Cosgrove et al., 2013; Hibbard and Greene, 2013). This is particularly true among older patients who often suffer multiple disease conditions. Moreover, engaging patients in the health management can have a pivotal role in improving the effectiveness and efficiency of care (Holman and Lorig, 2004; Remmers et al., 2009). It can also improve client's satisfaction with the care process and the maintenance of an active role in society (Mosen et al., 2007; Kubina et al., 2013). This may not only contribute to the reduction of direct costs of the healthcare system, but also concur with the (re)orientation of economic resources in the management of healthcare systems to reduce costs (Fisher et al., 2009; Remmers et al., 2009; Greene and Hibbard, 2012; Hibbard and Greene, 2013).

Not surprisingly, the importance of engaging patients in their care has been gaining increased attention from clinicians, researchers, and policymakers alike (Simmons et al., 2014; Weil, 2016). Different labels have been adopted in the scientific literature to denote the process of making patients active stakeholders of their health management (i.e., patient activation, patient empowerment, patient engagement, and patient involvement; Barello et al., 2014). Among these, the use of the term "patient engagement" has been showing an increasing trend, probably for its capacity to represent an "umbrella term" that encompasses different interconnected conceptualizations and labels (Barello et al., 2016). With this term, which is taken from the marketing literature (Hardyman et al., 2015), the dynamic relationship between the patient ("the supply") and the healthcare system ("the demand") and its multi-level determinants (individual, relational, contextual, organizational) are highlighted (Graffigna et al., 2014a, 2015). As showed by Graffigna et al. (2014b, p. 87), the phenomenon of patient engagement is a "multi-dimensional psychosocial process resulting from the conjoint cognitive, emotional, and behavioral enactment of individuals toward their health condition and management." According to this definition and to other authors' explanations of patient engagement (Hibbard et al., 2004; Gruman et al., 2010; Carman et al., 2013), three main dimensions featured the patient engagement process: behavioral (the concrete actions that patients do to manage their health condition), cognitive (the thoughts and information that patients have concerning their health condition), and emotional (the feelings and emotions that patients experience when adjusting to their new health condition) (Barello et al., 2016). All these dimensions help patients become experts in managing their health and care. According to this broad conceptualization and different qualitative studies on the care experiences of chronic patients, the Patient Health Engagement (PHE) Model has been developed (Graffigna et al., 2014a,b; Barello and Graffigna, 2015; Barello et al., 2015). According to this Model, after a diagnosis of chronic illness, people move through a series of phases that express different needs for engagement in care. In a blackout phase, patients feel unable to manage their health condition and are upset. Subsequently, they can experience an arousal phase in which they perceive anxiety and worry for their condition. In an adhesion phase, they learn to manage their health condition but have problems in adjusting their health habits to new life situations. Finally, in an eudemonic phase, they feel confident in autonomously managing their health conditions, they are optimistic about their future, and they perceive themselves as the main actors of their health and their life. A 5-items unidimensional validated self-report scale (PHE-Scale) has been recently validated strongly rooted in this model, showing the ability to detect these four main patient engagement phases along the care process (Graffigna et al., 2015).

However, the findings of a recent systematic review on patient engagement interventions revealed that although the link between patient engagement and improved health outcomes has been demonstrated, few interventions exist in the literature (Simmons et al., 2014). The few existing interventions target only some components and dimensions of the patient engagement process. This could limit the evidences of such interventions. Furthermore, few studies that aimed to engage patients rarely quantified and measured patient engagement (Simmons et al., 2014). Theoretical assumptions of those studies are often weak. Additionally, little research in this area has involved older people as the main target of the research (Wetzels et al., 2007). Besides the difficulties and specific needs that older patients may have to address in self-managing their health, specific solutions might be required for this population. Despite the considerable potential of patient engagement for older adults, this field remains underdeveloped (Kane and Kane, 2001; Elliott et al., 2016). To date, little is known about how to concretely engage older patients in their health management in a way that could be integrated in the clinical practice and tailored to the older patients' specific needs and goals.

This study reports on the design, development, and optimization processes of a new theory-driven intervention program aimed at improving the engagement of older chronic patients in care management. The intervention was based on the PHE Model, because of its broader view of the patient engagement process, and it proposed the operationalization of the PHE Model in practice based on three main research phases: literature review, experts and patients' opinion.

\section{METHODS}

\section{Study Design}

The Medical Research Council (MRC) Framework was used to assist with the development and optimization of an intervention program to improve the older chronic patients' engagement in 
health management. This phased approach aimed to provide a robust methodological basis for the development and evaluation of complex interventions (Campbell et al., 2000, 2007; Craig et al., 2008). According to the MRC framework, prior to formal evaluation, dissemination, and monitoring of a new intervention, two main steps in the development and modeling need to be implemented to identify the theoretical base for the intervention, define contents and processes, structure the intervention, and model the procedures according to stakeholders' evaluations. In this study, this development and optimization process featured three main research phases, evidence exploration, experts' tuneup, and patients' fine-tuning. For every phase, activities, aims, and methods are described in Table 1. A small team of health psychologists responsible for the coordination and project implementation discussed the key findings of every research phase. The results of these discussions were used to set up and gradually refine the resulting intervention.

\section{RESULTS}

The findings from the research phases, so as details about the resulting intervention, are presented in the following sections.

\section{Literature Review on Patient Engagement Techniques}

The synthesized literature evidence demonstrated that interventions to engage chronic patients in their health and care management at the individual level (i.e., the patient) were generally scant, often poorly described in their components and delivery, and rarely of high methodological quality. Furthermore, they rarely targeted specifically older patients.

Despite these aspects, some key components and techniques adopted by the identified interventions to engage patients in their health and care management recurred. Thus, after selecting articles describing interventions for patient engagement, we analyzed and extracted the techniques used by the selected interventions. We thereafter summarized those techniques and synthetized them considering the three main domains of the patient engagement process:

- behavioral (the concrete actions that patients do to manage their health condition),

- cognitive (the thoughts and information that patients have concerning their health condition), and

- emotional (the feelings and emotions that patients experience when adjusting to their new health condition).

TABLE 1 | Methodological process for intervention development and modeling.

\begin{tabular}{|c|c|c|c|}
\hline Phase & Activity & Aims & Methods \\
\hline $\begin{array}{l}\text { Phase 1: "Evidences } \\
\text { exploration" }\end{array}$ & $\begin{array}{l}\text { Systematic literature } \\
\text { review }\end{array}$ & $\begin{array}{l}\text { (i) To identify existing strategies, techniques and } \\
\text { solutions for patient engagement } \\
\text { (ii) To match literature findings with the PHE } \\
\text { model components }\end{array}$ & $\begin{array}{l}\text { - Scientific databases: Medline, Psychlnfo, Scopus, Cochrane. } \\
\text { - Search strategy: ("patient engagement" OR "patient activation") } \\
\text { AND ("intervention" OR "trial” OR "program*”) } \\
\text { - Inclusion criteria: (i) involving chronic patients, } \\
\text { (ii) pre-/post-evaluations }\end{array}$ \\
\hline
\end{tabular}

Phase 2: "Tune-up Experts' group with experts" discussion (i) To revise, discuss and prioritize results of Phase 1

(ii) To optimize intervention's contents and procedures

(iii) To collect experts' opinion about feasibility of the interventions' components
- Participants: 22 healthcare professionals caring for older patients trained in patient engagement theories, measures, and actions

Procedures: (i) presentation of literature results, (ii) group discussion to revise and optimize evidence-based results,

(iii) ad-hoc questionnaire to evaluate feasibility, utility and adoption of an intervention for patient engagement - Data analysis: transcription of group discussion was thematically analyzed by members of the research team (JM, GG) to identify key issues within data (Braun and Clarke, 2006); quantitative data gathered through the evaluation sheets were synthetized with descriptive analyses by using the SPSS software 21.0.
Phase 3: "Fine tuning with patients"
Repeated qualitative semi-structured interviews (i) To explore older patients' expectations and needs for engagement

(ii) To collect patients' opinion about comprehensibility and acceptability of the intervention

(iii) To collect patients' feedback to optimize the intervention
Participants: 8 purposively selected patients $>65$ years-old affected by at least one chronic condition

Procedures: (i) preliminary qualitative semi-structured interview lasting about 30 minutes before the involvement in a prototype training,

(ii) prototype training simulation (patients participated in a prototype version of the training),

(iii) qualitative semi-structured interview lasting about 60 min just after the second session of the prototype training

Data analysis: Two researchers independently analyzed interviews by using audiotape transcripts of interviews. A thematic approach was adopted in order to synthetize main themes within data (Braun and Clarke, 2006). 
Most interventions targeted the behavioral and/or cognitive domains. Consequently, positive psychology exercises (Seligman et al., 2005; Sin and Lyubomirsky, 2009; Schueller and Parks, 2012) and expressive writing tasks (Pennebaker and Beall, 1986; Rosenberg et al., 2002; Frisina et al., 2004) were also included within the emotional part of our intervention because they showed promising results in helping patients positively adjust to their illness experience. Furthermore, the main theories and models on which the programs were based and used to elucidate the role of cognitive, emotional, and social factors in health behavior were summarized. Table 2 describes the resulting map of techniques reported in the scientific literature and used to deliver interventions for patient engagement.

Personalization of actions based on baselines assessment level was also adopted in some analyzed studies to ensure that actions were tailored to participants' experiences (Hibbard et al., 2004; Rise et al., 2016).

Finally, literature reported that even relatively short interventions could increase patient engagement, and suggested to track patient engagement and specific behavioral outcomes over time using validated measures to achieve positive health outcomes (Simmons et al., 2014).

\section{Healthcare Professionals' Tune-Up}

Overall, 22 healthcare professionals (e.g., nurses, physicians) who were experts in patient engagement theories and strategies participated in the prototype intervention's presentation and evaluation. These were community based practitioners caring for older chronic patients in a North-Italian hospital who were previously involved in a formative program on patient engagement theories, measures, and strategies. The researchers (JM, GG) recruited willing participants, most of whom were women $(72 \%)$ with the mean age of 46 years old (range: 29-62), and with the mean number of years of experience of 26 years. Evidence-based literature on patient engagement strategies/techniques and suggested exercises based on summarized techniques were presented to experts. These exercises were a prototype version of those ones described in the last section of the results and in Table 7. Thereafter, they were invited to discuss the presented input, to revise the proposed framework, to provide suggestions about possible ameliorations, and to identify possible advantages/barriers to the implementation of an intervention including the revised techniques. Subsequently, experts discussed a prototype of training's contents and procedures in small groups and finally evaluated the prototype intervention using a worksheet that was developed ad-hoc to address the following domains: easiness to use, relevance and utility, perceived competence, and willingness of adoption.

Generally, experts evaluated the proposed techniques and the framework of action positively. They particularly appreciated standardization and documentation of procedures and the possibility offered by techniques and proposed exercises to support the patient through simple and concrete steps and tasks. Thereafter, they provided suggestions and recommendations for the training's contents and procedures. The main themes that emerged from group discussion are summarized in Table 3 with corresponding quotes.

Finally, on average, experts rated the proposed prototype intervention on a 5-point Likert scale as highly relevant and useful (ranging from moderately to extremely), and they reported high willingness to implement the training in their clinical practice (ranging from moderately to extremely). They generally evaluated the exercises as moderately easy to use (ranging from slightly to very) and felt moderately able to deliver them (ranging from slightly to very) (see Figure 1).

\section{Listening Older Patients: Fine Tuning the Intervention} Eight participants older than 65 years accepted to participate in the "fine tuning" phase. Those patients were purposively and sequentially recruited by an external researcher through community senior centers, senior associations, or community medical centers. No exclusion criteria with the exception of age ( $>65$ years old) or diagnosis ( $>1$ chronic health condition) were applied. Most participants were women (72\%), affected

TABLE 2 | Main techniques and theories emerged from literature considering the three PHE domains.

\begin{tabular}{|c|c|c|}
\hline PHE domains & Techniques & Theories/Models \\
\hline Behavioral & $\begin{array}{l}\text { - Goal setting and planning (Shively et al., 2005, 2013; Riegel et al., } \\
\text { 2006; Kersten et al., 2015; Shah et al., 2015) } \\
\text { - Motivational interviewing (Anderson et al., 1995; Riegel et al., 2006; } \\
\text { Linden et al., 2010; Benzo et al., 2012) }\end{array}$ & $\begin{array}{l}\text { Patient Activation Theory (Hibbard et al., 2004) } \\
\text { Transtheoretical Model (Prochaska and DiClemente, 1986) } \\
\text { Self-Regulation Theory (Leventhal, 1984) }\end{array}$ \\
\hline Cognitive & $\begin{array}{l}\text { - Question-asking tasks (Hochhalter et al., 2010; Deen et al., 2011; } \\
\text { Maranda et al., 2014; Maclachlan et al., 2016) } \\
\text { - Psycho-education sessions (Druss et al., 2010; Maindal et al., 2011; } \\
\text { O'Leary et al., 2015; Krouse et al., 2016; Lara-Cabrera et al., 2016) } \\
\text { - Salutogenesis exercises to map external resources (Tan et al., 2016) } \\
\text { - DaiOly diaries for self-monitoring (Nagykaldi et al., 2012; Lee et al., 2013) }\end{array}$ & $\begin{array}{l}\text { Health Belief Model (Janz and Becker, 1984) } \\
\text { Patient Activation Theory (Hibbard et al., 2004) } \\
\text { Social Cognitive Theory (Bandura, 1986) } \\
\text { Self-determination Theory (Deci and Ryan, 2008) }\end{array}$ \\
\hline Emotional & $\begin{array}{l}\text { - Positive psychology exercises } \\
\text { - Expressive writing tasks } \\
\text { - Salutogenesis exercises to strengthen inner resources (Tan et al., 2016) } \\
\text { - Illness experience maps (Hall et al., 2015) }\end{array}$ & $\begin{array}{l}\text { Stress Coping Model (Lazarus and Folkman, 1984) } \\
\text { Salutogenesis (Antonovsky, 1996) } \\
\text { Positive Psychology (Seligman and Csikszentmihalyi, 2014) }\end{array}$ \\
\hline
\end{tabular}


TABLE 3 | Experts' recommendations main themes and quotes.

\begin{tabular}{|c|c|}
\hline Main themes & Quotes \\
\hline $\begin{array}{l}\text { An evidence-based standardized } \\
\text { guide to follow }\end{array}$ & $\begin{array}{l}\text { "All the proposed exercises are reported in literature and have a solid background, this helps" } \\
\text { "It's easier to follow the program if exercises and procedures are well described" }\end{array}$ \\
\hline Working on multiple domains & $\begin{array}{l}\text { "I think that the most valuable aspect of the intervention could really be that it allows working on different aspects of the patient's } \\
\text { experience" } \\
\text { "I know that my patient has different need, and it's important to me to offer him actions for all his/her different needs" } \\
\text { "It's true that patients need to be informed, but also to understand what is happening to them" }\end{array}$ \\
\hline Optimizing available resources & $\begin{array}{l}\text { "I usually do most of the things you described, but I do them without thinking... having a guide could help me better organizing my } \\
\text { actions" } \\
\text { "Most of the aids are already available to the patient, but he/she doesn't know that there are and how to use them" }\end{array}$ \\
\hline $\begin{array}{l}\text { Supporting good communication } \\
\text { exchanges }\end{array}$ & $\begin{array}{l}\text { "Some exercises are like a guide for our exchanges with the patient" } \\
\text { "This can help having a guide for my communication with the patient...l already ask to my patient his story, but with some of these } \\
\text { exercises I can have some practical tool" }\end{array}$ \\
\hline A tool to create bridges & $\begin{array}{l}\text { "Results of assessment and exercises can be used by other colleagues to continue the work with the patient" } \\
\text { "Patients can feel accompanied by professionals also outside the hospital bridges, it can be a way to stay in touch with the patient }\end{array}$ \\
\hline Motivating patients to change & $\begin{array}{l}\text { "the process of patient engagement could require a pre-existing degree of motivation on the individuals' part" } \\
\text { "it's important to consider motivation of patients" }\end{array}$ \\
\hline Autonomy vs. presence & $\begin{array}{l}\text { "the illness experience map is useful if you use it in the first encounter with the patient" } \\
\text { "I think that this intervention is easily suitable and implementable in clinical practice, but time and spaces are surely a potential } \\
\text { barrier... I appreciate that some exercises can be autonomously managed by the patient" } \\
\text { "Is useful to give to the patient some at-home exercises, it could be a way for the patient to bring patient engagement into the hom } \\
\text { walls" }\end{array}$ \\
\hline $\begin{array}{l}\text { Supporting a patient-centered } \\
\text { organizational culture }\end{array}$ & $\begin{array}{l}\text { "we are speaking about a cultural change" } \\
\text { "we need an organizational structure supporting the introduction of a similar training" } \\
\text { "looking only to the disease can be a barrier, professionals should be trained to support a patient-centered culture" }\end{array}$ \\
\hline $\begin{array}{l}\text { Working in tandem with patients } \\
\text { and caregivers }\end{array}$ & $\begin{array}{l}\text { "you know...most of my patients are older...some of them have a low educational level, live far from the hospital, or have impairing } \\
\text { conditions... What about a training also for caregivers?" } \\
\text { "I think it could be useful for our population of patients to train also caregivers" }\end{array}$ \\
\hline
\end{tabular}

"think it could be useful for our population of patients to train also caregivers"

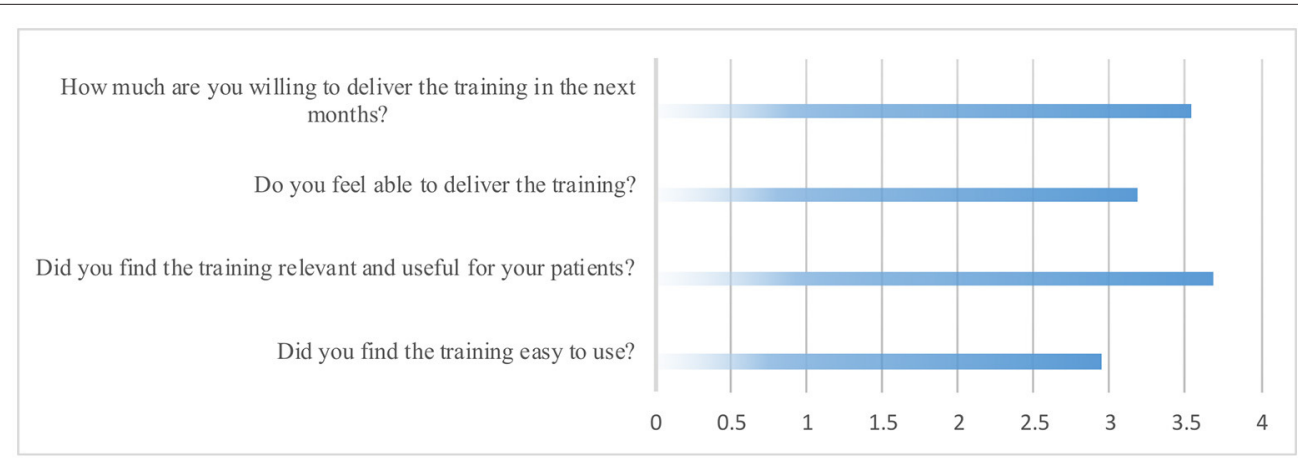

FIGURE 1 | Healthcare professionals' evaluations responses.

primarily by type 2 diabetes (57\%). Most had an elementary education (57\%), and indicated that they were married (71\%). All of them were retired. Three participants were overweight, but none of them was a smoker. Almost all participants had multiple diseases and comorbidities, mainly with cardiovascular disorders. For further details about the characteristics of the sample, see Table 4.
Participants completed two face-to-face semi-structured qualitative interviews conducted in their homes just before and just after the involvement in a simulation of the prototype training (this was a second generation prototype version of the training modified based on the experts' revision of the primary generation prototype training) and participated in the presentation of the training's materials and 
procedures (see Table 5 for further details about the interviews' track).

The first interviews round aimed to elicit the needs and expectations for engagement among participants. All participants reported interest in participating in an intervention designed to engage them in their health management with different motivations ("to become more calm, I'm too anxious when I manage my health," "to succeed in changing my lifestyle according to my health condition," and "I'm really upset, I need to understand what it is happening to me and reorganize my life"). They did not have particular expectations for a patient engagement intervention. Most of them (57\%) preferred an individual intervention.

TABLE 4 | Characteristics of participants $(n=8)$.

\begin{tabular}{lc}
\hline & mean (SD)/ $\boldsymbol{n}(\%)$ \\
\hline Age & $73(4)$ \\
SEX & \\
Male & $2(25 \%)$ \\
Female & $6(75 \%)$ \\
Education (years) & $8(4)$ \\
DIAGNOSIS & \\
Type 2 diabetes & $4(50 \%)$ \\
Cardiovascular disease & $2(25 \%)$ \\
Chronic respiratory disease & $1(12,5 \%)$ \\
Inflammatory bowel disease & $1(12,5 \%)$
\end{tabular}

After this preliminary interview, patients were invited to participate in a simulation of the prototype training and to adopt the developed at-home exercises in their daily life. Patients were also asked to complete a battery of questionnaires before and after the prototype training to evaluate the potential compilation burden and the feasibility of measures. Participants were informed that the training would have been refining basing on their feedbacks and invited to point out possible difficulties with comprehension or other aspects of the program. One month after the preliminary interview and the involvement in the first prototype session, patients participated in the second prototype intervention session followed by a second round of interviews in which materials and procedures were discussed with patients.

The responses to the intervention were generally positive. Adherence to the home practice was high, as all participants used all of the provided instruments and engaged in a sustained effort to pursue their health goals. Table 6 summarizes the main themes that emerged from this second round of interviews.

The average response for recommending the training to another person was high. In particular, participants indicated that they would suggest the intervention to just diagnosed people and to people who are less interested in managing their health, although those people were also perceived as difficult to engage in the intervention.

\section{"PHEinAction": An Intervention for Older People Health Engagement}

According to the main results of the previously described research phases, the prototype version of the training, which was

TABLE 5 | Interviews' guide.

\begin{tabular}{|c|c|}
\hline Area & Exemplificative questions \\
\hline \multicolumn{2}{|l|}{ PRELIMINARY INTERVIEW } \\
\hline Experiences and needs for engagement & $\begin{array}{l}\text { - In your experience, what would help one in being more engaged in managing his/her health? } \\
\text { - What would help you in being more engaged? } \\
\text { health management? Why would you engage in efforts to be more involved in your health } \\
\text { management? }\end{array}$ \\
\hline Expectations for a patient engagement intervention & $\begin{array}{l}\text { - What features should have an intervention to engage you in managing your health? } \\
\text { - Which contents and which way of delivery would you prefer? }\end{array}$ \\
\hline \multicolumn{2}{|l|}{ SECONDARY INTERVIEW } \\
\hline Patients' experiences about their participation in the intervention & $\begin{array}{l}\text { - Could you describe me the main reasons which bring you in participating in the intervention? } \\
\text { - Could you describe what happens in the sessions, in your own words? } \\
\text { - How did you feel when you participate in the intervention? How did you feel before and after } \\
\text { starting the sessions? } \\
\text { - If you had to describe what the intervention means to you, what would you say? What } \\
\text { images/metaphors come to your mind? }\end{array}$ \\
\hline The intervention effects on the daily life and on health management & $\begin{array}{l}\text { - In your opinion, how the intervention improved your engagement and attitude toward } \\
\text { managing your health? How did it affect your daily life? } \\
\text { - If you think about your way of managing your health, what aspects of the intervention have } \\
\text { contributed to it? How? } \\
\text { contributed to them? How? }\end{array}$ \\
\hline Intervention satisfaction and feedbacks & $\begin{array}{l}\text { - How would you rate and define your satisfaction toward the intervention? What aspects } \\
\text { satisfied you more? What satisfied you less? Why? } \\
\text { - What were the obstacles and difficulties? } \\
\text { - What would you change or improve? }\end{array}$ \\
\hline
\end{tabular}


TABLE 6 | Main themes and quotes of patients' perception of the intervention.

\begin{tabular}{|c|c|}
\hline Main themes & Quotes \\
\hline $\begin{array}{l}\text { A new perspective to the } \\
\text { disease }\end{array}$ & $\begin{array}{l}\text { "I already knew all these things, but I kept them insight myself and gave no importance to them, with this intervention I eviscerate them } \\
\text { and thus I faced them" (Int. 1, F, } 77 \text { years-old) } \\
\text { "It was important to me because I slowed down and I reflected on my situation, it was difficult but important and satisfactory" (Int. } 6 \text {, F, } 68 \\
\text { years-old) } \\
\text { "it is now for me like some light into the fog is appearing... and this light changes your perspective...it is like I'm realizing some things" (Int. } \\
\text { 2, F, } 69 \text { years-old) }\end{array}$ \\
\hline A stimulus to change & $\begin{array}{l}\text { "it was useful for me to manage my emotions and my anger...it helped me" (Int. 5, F, } 70 \text { years-old) } \\
\text { "I want to thank you because I never thought to be able to do something to better manage my health" (Int. 2, F, } 69 \text { years-old) } \\
\text { "it was like a flowered field with the sun...this pathway made me serene" (Int. 1, F, } 77 \text { years-old) }\end{array}$ \\
\hline $\begin{array}{l}\text { Clinicians have to play } \\
\text { their part }\end{array}$ & $\begin{array}{l}\text { "doctors did not play their part" (Int. 3, M, } 76 \text { years-old) } \\
\text { "asking questions to my doctor is hard, I prepared myself for the doctor's visit but the encounter was brief and it ended on the hoof" (Int. } \\
\text { 2, F, } 69 \text { years-old) }\end{array}$ \\
\hline $\begin{array}{l}\text { Improving repetitiveness } \\
\text { and comprehensibility }\end{array}$ & $\begin{array}{l}\text { "sometimes home-works appeared repetitive and I would have benefitted by more concise exercises" (Int. 6, F, } 68 \text { years-old) } \\
\text { "I only completed the elementary degree so some words were difficult to me to understand" (Int. 5, F, } 70 \text { years-old) }\end{array}$ \\
\hline
\end{tabular}

outlined based on the PHE theory and literature analysis, was finally refined.

The resulting intervention was an individual training consisting of 2 monthly 1 -h sessions, one brief telephonic consultation between the two sessions, and a set of instruments to be used by participants at home. Each encounter contributed to the promotion of manageability and meaningfulness disposition to manage health.

The first face-to-face session was used to (i) collect information on the patient's background through a patient's experience map, (ii) assess the starting phase of engagement of participants (i.e., blackout phase, arousal phase, adhesion phase, eudaimonic project phase) through a structured and validated questionnaire (The PHE Scale of Graffigna et al., 2015), (iii) define a purpose of engagement and manageable behaviors to sustain this purpose, and (iv) administer the instruments to support those purpose and behaviors based on the baseline PHE phase. Thus, for every phase of engagement, an individually tailored goal with subsequent emotional, informational, and behavioral actions was defined. Goals and behaviors defined in the individual sessions were based on the PHE phase of participants and were driven by PHE theory. The contract regarding the defined goals and behaviors was made with participants according to their particular needs and expectations for care. Furthermore, for every goal and actions, a set of instruments was developed to sustain the PHE process at home. Those instruments were developed based on the literature review of the existing strategies/techniques adopted to engage patients in their care management (see Table 2) and on experts and patients' feedbacks. Following the PHE theory, they covered three main areas of action (i.e., emotional adjustment, health information seeking and use, and health behavior change). For every area, instruments were personalized to each of the four PHE phases, yielding four packages of instruments that became increasingly challenging across phases. Indeed, as suggested by the literature and endorsed by experts, personalization of actions based on PHE phases and consequently on patients' needs and desires for care was considered a key aspect of the intervention. Four different paths of training, with specific goals and consequent specific selection of exercises related to each area of action, were thus featured to enhance flexibility and personalization of the intervention (see Figure 2 for further details about the main goals of the four training's paths based on the baseline PHE phase of participants). During the first session, a personalized PHE plan was thus defined with home-based exercises. Participants were invited to follow their plan in the next month and to actively adopt instruments of their plan to reach their engagement goal. Table 7 provides further details about the instruments' aims and contents.

A telephonic consultation was conducted 2 weeks after the first encounter to maintain motivation of participants and discuss potential difficulties.

Finally, a second face-to-face session was used to (i) collect the experience of participants and discuss the adopted instruments, (ii) re-assess the PHE phase of participants through the PHEScale, (iii) provide feedbacks and reinforce improvements, and (iv) define a new engagement goal with related actions and instruments.

Figure 3 provides further details about the structure and the sessions' goals of the final intervention.

These two sessions were conceived to be the minimal unit of action for the patient engagement change, and further "units of actions" were suggested in critical points of the care process to sustain the change process.

\section{DISCUSSION}

This paper describes the process of the development and refinement of a theory-based individual training aimed to engage older chronically ill patients in their health and care management. To our knowledge, this is the first intervention that aims to sustain health engagement among older chronic population. The development process allowed to define, refine, and optimize the contents of the training. Overall, patients and healthcare professionals provided positive feedbacks for the 


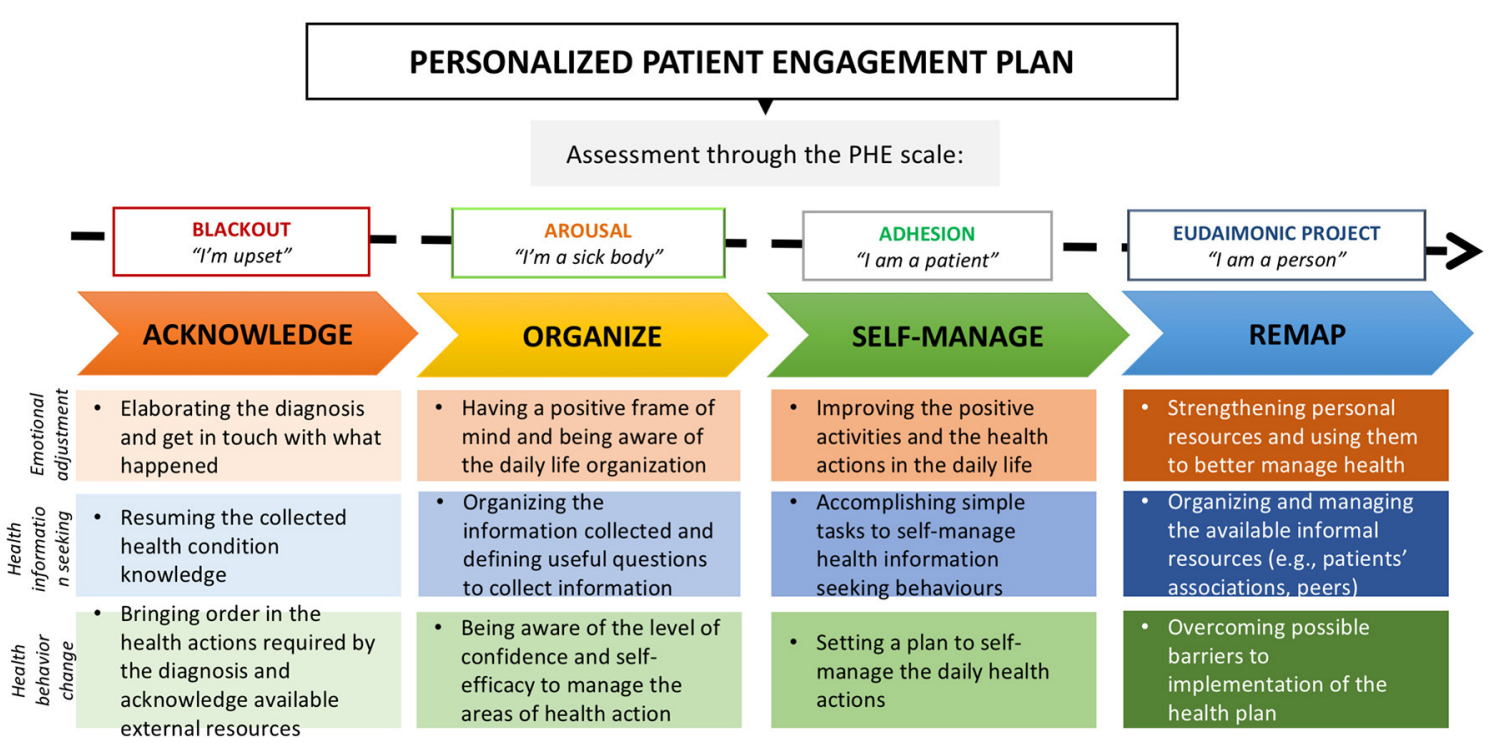

FIGURE 2 | The personalized patient engagement plan: Goals of the four training's paths basing on the baseline PHE phase.

TABLE 7 | "PHEinAction" home-based instruments' key components, aims and procedures.

\begin{tabular}{lll}
\hline Instruments & Aims & Exercises \\
\hline Instrument 1. & - To foster a process of adjustment to the & 1) Expressive writing exercise on the illness experience; \\
Emotional adjustment & diagnosis and to the patient's role & 2) Daily diary with small positive thinking tasks; \\
& $\begin{array}{ll}\text { - To activate and strengthen skills and inner } \\
\text { resources of the patient }\end{array}$ & $\begin{array}{l}\text { 3) Map of wellbeing/discomfort areas in the daily life and strengthening } \\
\text { exercise of wellbeing areas; }\end{array}$ \\
& $\begin{array}{l}\text { 4) Positive psychology exercise to identify } 3 \text { personal strengths and apply } \\
\text { them to better manage health }\end{array}$
\end{tabular}

Instrument 2.

Health information seeking and use

- To improve health information seeking/use processes

- To sustain the adoption of external resources

Instrument 3 .

Health behavior change
- To sustain the plan and organization of health behaviors

- To improve self-efficacy in managing health
1) Disease knowledge elicitation exercise;

2) Question-asking exercise;

3) Prompts to self-manage information-seeking behaviors;

4) Map of adopted informal information channels (e.g., internet, peers, books...)

1) Map of areas of action that patient needs to manage (diet, physical activity, medications...) and of informal resources supporting the management of these areas;

2) Self-evaluation exercise concerning self-efficacy level for every area of action that patients need to manage and identification of reasons for self-evaluation;

3) Behavioral plan to activate health actions;

4) Imagination exercise of possible barriers getting in the way for the plan and of solutions to handle these barriers training contents and procedures. The training still requires formal evaluation.

The development process highlighted some key points that to our opinion need to be discussed.

First, although the training was initially developed for patients affected by different chronic conditions, and no differences in the fruition of the intervention among the different clinical conditions were found, it might need to be adjusted to specific chronic conditions to enhance potential benefits of the training. Even more, the results revealed that the few months following the diagnosis can represent an optimal window of action to deliver the training. This is supported by the literature suggesting that the period just after diagnosis is particularly important to allow a process of diagnosis adjustment to be started (de Ridder et al., 2008). This should be tested by further studies and evaluations.

Second, experts envisaged families and caregivers as crucial to sustain patient engagement, especially in situations in which patients are physically compromised. Probably, a training could be specifically developed to engage also caregivers and families in the care process to better sustain patient engagement. As 


\section{The "PHEinAction" pathway}

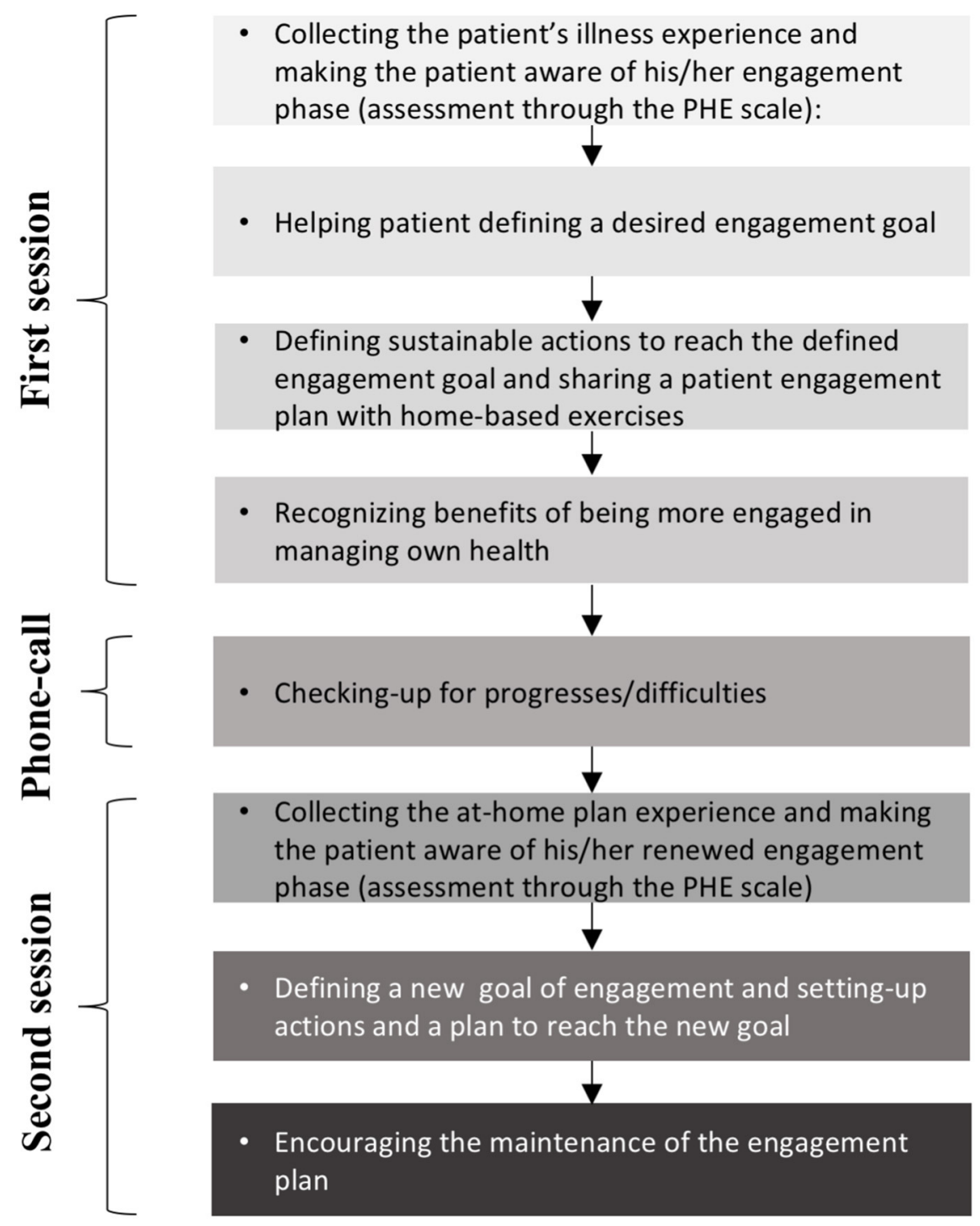

FIGURE 3 | The "PHEinAction" pathway: training structure and main sessions goals.

highlighted in the literature, giving support, and engaging families and caregivers could help ensure high-quality care at home (Wellard and Street, 1999; Donelan et al., 2002), thus strengthening the engagement of patients and supporting them when directly engaging them is hindered by physical or contextual barriers.

Third, clinicians were described by patients as a potential barrier to change in patient engagement. Complex programs that train clinicians to embrace requests of patients for engagement and, even more, enable patients to become partners in their care management could make patient engagement more effective.
The role of clinicians in advancing the patient engagement have been increasingly emphasized, as they play a crucial role in guiding patients on their care journey (Greene and Yedidia, 2005; Killaspy et al., 2015).

Finally, it is important to consider that this study aimed to report the development and refinement process of a new intervention, rather than to quantitatively evaluate its effect on validated measures. More data are needed to demonstrate the effectiveness of the intervention, especially in the long term, and to drive conclusions. The limited sample size (and the broadness of the inclusion criteria) did not allow us to 
make conclusions on the efficacy of the program. Patients' views expressed in this study were from a particular sample, mainly woman, and it was difficult to retrieve recently diagnosed participants. Furthermore, patients' feedback recorded in this study was qualitative in nature, and as such, it needs to be complemented by quantitative evaluations. The intervention needs to be further evaluated using a larger sample of males and females with different degree of engagement at baseline and including also recently diagnosed patients. It would be advisable to test the feasibility of the intervention in more homogeneous populations. Furthermore,-although this was not the primarily aim of this study-preliminary results collected through the PHE Scale suggested few changes in the engagement scores of patients enrolled in the intervention. In particular, only patients with lower levels of engagement at baseline improved their scores after the training. Participants reporting high levels of engagement at baseline (equal to or greater than the adhesion phase measured through the PHE scale) generally maintained their baseline scores after the training. This is consistent with other studies showing that particularly less engaged patients might benefit from activation interventions (Deen et al., 2011). A more systematic effectiveness study is needed to explore the stability of these first preliminary results. Additionally, changes in engagement scores might need more time to be detected, and follow-up evaluations could be particularly relevant when conducting a similar training.

To conclude, this study described the development process and optimization of a new individual intervention program to engage older chronic patients in their care management. The study utilized a step-wise structured approach to develop

\section{REFERENCES}

Anderson, R. M., and Funnell, M. M. (2005). Patient empowerment: reflections on the challenge of fostering the adoption of a new paradigm. Patient Educ. Couns. 57, 153-157. doi: 10.1016/j.pec.2004.05.008

Anderson, R. M., Funnell, M. M., and Butler, P. M. (1995). Patient empowerment. Results of a randomised controlled trial. Diabetes Care. 18, 943-949.

Antonovsky, A. (1996). The salutogenic model as a theory to guide health promotion. Health Promot. Int. 11, 11-18. doi: 10.1093/heapro/11.1.11

Bandura, A. (1986). Social Foundations of Thought and Action: A Social Cognitive Theory. Englewood Cliffs, NJ: Prentice-Hall, Inc.

Barello, S., and Graffigna, G. (2015). Engaging patients to recover life projectuality: an Italian cross-disease framework. Qual. Life Res. 24, 1087-1096. doi: 10.1007/s11136-014-0846-x

Barello, S., Graffigna, G., Vegni, E., and Bosio, A. C. (2014). The challenges of conceptualizing patient engagement in healthcare: a lexicographic literature review. J. Partic. Med. 6:e9. Available online at: http://www.jopm.org/evidence/ reviews/2014/06/11/the-challenges-of-conceptualizing-patient-engagement-inhealth-care-a-lexicographic-literature-review/

Barello, S., Graffigna, G., Vegni, E., Savarese, M., Lombardi, F., and Bosio, A. C. (2015). 'Engage me in taking care of my heart': a grounded theory study on patient-cardiologist relationship in the hospital management of heart failure. BMJ Open. 5:e005582. doi: 10.1136/bmjopen-2014-0 05582

Barello, S., Triberti, S., Graffigna, G., Libreri, C., Serino, S., Hibbard, J., et al. (2016). eHealth for patient engagement: a systematic review. Front. Psychol. 8:6. doi: 10.3389/fpsyg.2015.02013

Benzo, R., Vickers, K., Ernst, D., Tucker, S., McEvoy, C., and Lorig, K. (2012). Development and feasibility of a self-management intervention complex interventions (MRC) and a theoretical model based on qualitative studies and grounded on the specific needs of the target group. Indeed, grounding health interventions on qualitatively-based theories and adjusting them to the specific needs and context of final users can help deliver ecological studies. The intervention components, developed and evaluated by experts and older patients, were considered feasible and acceptable as well asuseful and easily implementable in clinical practice. Some suggestions for changes in health actions and attitudes after the training were also envisaged. Further work is needed to improve and adapt the intervention components and tackle issues related to their delivery and implementation within healthcare professionals' existing clinical practice.

\section{AUTHOR CONTRIBUTIONS}

GG and JM designed the study and developed the methodology. JM collected the data, performed the analysis, and wrote the manuscript. GG supervised the data collection and analysis process, and revised the manuscript.

\section{ACKNOWLEDGMENTS}

We are particularly thankful to professionals and patients who gave consent to participate in the study for the kind participation to the project and for the precious feedbacks given to refine the training. We would also like to thank Serena Barello for her contribution to the development processes and Enrica Rottigni for her support to the qualitative phases of the study.

for chronic obstructive pulmonary disease delivered with motivational interviewing strategies. J. Cardiopulm. Rehabil. Prev. 33, 113-123. doi: 10.1097/HCR.0b013e318284ec67

Braun, V., and Clarke, V. (2006). Using thematic analysis in psychology. Qual. Res. Psychol. 3, 77-101. doi: 10.1191/1478088706qp063oa

Campbell, M., Fitzpatrick R, Haines A, Kinmonth AL, Sandercock P, Spiegelhalter D, et al. (2000). Framework for design and evaluation of complex interventions to improve health. BMJ 16:321. doi: 10.1136/bmj.321.7262.694

Campbell, N. C., Murray, E., Darbyshire, J., Emery, J., Farmer, A., Griffiths, F., et al. (2007). Designing and evaluating complex interventions to improve health care. BMJ 334, 455-459. doi: 10.1136/bmj.39108.379965.BE

Carman, K. L., Dardess, P., Maurer, M., Sofaer, S., Adams, K., Bechtel, C., et al. (2013). Patient and family engagement: a framework for understanding the elements and developing interventions and policies. Health Aff. 32, 223-231. doi: 10.1377/hlthaff.2012.1133

Chatterji, S., Byles, J., Cutler, D., Seeman, T., and Verdes, E. (2015). Health, functioning, and disability in older adults-present status and future implications. Lancet 385, 563-575. doi: 10.1016/S0140-6736(14)61462-8

Cosgrove, D. M., Fisher, M., Gabow, P., Gottlieb, G., Halvorson, G. C., James, B. C., et al. (2013). Ten strategies to lower costs, improve quality, and engage patients: the view from leading health system CEOs. Health Aff. 32, 321-327. doi: $10.1377 /$ hlthaff.2012.1074

Coulter, A. (2005). What do patients and the public want from primary care?. BMJ 331, 1199-1201. doi: 10.1136/bmj.331.7526.1199

Coulter, A. (2012). Patient engagement-what works?. J. Ambul. Care Manage. 35, 80-89. doi: 10.1097/JAC.0b013e318249e0fd

Craig, P., Dieppe, P., Macintyre, S., Michie, S., Nazareth, I., and Petticrew, M. (2008). Developing and evaluating complex interventions: the new Medical Research Council guidance. BMJ 29:337. doi: 10.1136/bmj.a1655 
Deci, E. L., and Ryan, R. M. (2008). Self-determination theory: a macrotheory of human motivation, development, and health. Can. Psychol. 49:182. doi: $10.1037 / \mathrm{a} 0012801$

Deen, D., Lu, W. H., Rothstein, D., Santana, L., and Gold, M. R. (2011). Asking questions: the effect of a brief intervention in community health centers on patient activation. Patient Educ. Couns. 84, 257-260. doi: 10.1016/j.pec.2010.07.026

Denton, F. T., and Spencer, B. G. (2010). Chronic health conditions: changing prevalence in an aging population and some implications for the delivery of health care services. Can. J. Aging 29:11. doi: 10.1017/S0714980809990390

de Ridder, D., Geenen, R., Kuijer, R., and van Middendorp, H. (2008). Psychological adjustment to chronic disease. Lancet 372, 246-255. doi: 10.1016/S0140-6736(08)61078-8

Donelan, K., Hill, C. A., Hoffman, C., Scoles, K., Feldman, P. H., Levine, C., et al. (2002). Challenged to care: Informal caregivers in a changing health system. Health Aff. 21, 222-231. doi: 10.1377/hlthaff.21.4.222

Druss, B. G., Zhao, L., Silke, A., Bona, J. R., Fricks, L., Jenkins-Tucker, S., et al. (2010). The Health and Recovery Peer (HARP) Program: a peer-led intervention to improve medical self-management for persons with serious mental illness. Schizophr. Res. 118, 264-270. doi: 10.1016/j.schres.2010.01.026

Ebrahim, S. (1997). Public health implications of ageing. J. Epidemiol. Community Health 51, 469-472. doi: 10.1136/jech.51.5.469-a

Elliott, J., McNeil, H., Ashbourne, J., Huson, K., Boscart, V., and Stolee, P. (2016). Engaging older adults in health care decision-making: a realist synthesis. PCORI 2, 1-11. doi: 10.1007/s40271-016-0168-x

Fisher, E. S., McClellan, M. B., Bertko, J., Lieberman, S. M., Lee, J. J., Lewis, J. L., et al. (2009). Fostering accountable health care: moving forward in medicare. Health Aff. 28, w219-w231. doi: 10.1377/hlthaff.28.2.w219

Frisina, P. G., Borod, J. C., and Lepore, S. J. (2004). A meta-analysis of the effects of written emotional disclosure on the health outcomes of clinical populations. J. Nerv. Ment. Dis. 192, 629-634. doi: 10.1097/01.nmd.0000138317.30764.63

Graffigna, G., Barello, S., Bonanomi, A., and Lozza, E. (2015). Measuring patient engagement: development and psychometric properties of the Patient Health Engagement (PHE) scale. Front. Psychol. 6:274. doi: 10.3389/fpsyg.2015.00274

Graffigna, G., Barello, S., Libreri, C., and Bosio, C. A. (2014b). How to engage type2 diabetic patients in their own health management: implications for clinical practice. BMC Public Health 14:648. doi: 10.1186/1471-2458-14-648

Graffigna, G., Barello, S., Riva, G., and Bosio, A. C. (2014a). "Patient engagement: the key to redesign the exchange between the demand and supply for healthcare in the era of active ageing," in Active Ageing and Healthy Living: A Human Centered Approach in Research and Innovation as Source of Quality of Life, Vol. 203, eds G. Riva, P. Ajmone Marsan, and C. Grassi (Netherlands: IOS Press), $85-95$.

Greene, J., and Hibbard, J. H. (2012). Why does patient activation matter? An examination of the relationships between patient activation and health-related outcomes. J. Gen. Intern. Med. 27, 520-526. doi: 10.1007/s11606-011-1931-2

Greene, J., and Yedidia, M. J. (2005). Provider behaviors contributing to patient self-management of chronic illness among underserved populations. J. Health Care Poor Underserved. 16, 808-824. doi: 10.1353/hpu.2005.0097

Gruman, J., Rovner, M. H., French, M. E., Jeffress, D., Sofaer, S., Shaller, D., et al. (2010). From patient education to patient engagement: implications for the field of patient education. Patient Educ Counsel. 78, 350-356. doi: 10.1016/j.pec.2010.02.002

Hall, L. K., Kunz, B. F., Davis, E. V., Dawson, R. I., and Powers, R. S. (2015). The cancer experience map: an approach to including the patient voice in supportive care solutions. J. Med. Internet Res. 17:e132 doi: 10.2196/jmir.3652

Hardyman, W., Daunt, K. L., and Kitchener, M. (2015). Value co-creation through patient engagement in health care: a micro-level approach and research agenda. Public Manag. Rev. 17, 90-107. doi: 10.1080/14719037.2014.881539

Hibbard, J. H., and Cunningham, P. J. (2008). How engaged are consumers in their health and health care, and why does it matter. Res. Briefs. 8, 1-9.

Hibbard, J. H., and Greene, J. (2013). What the evidence shows about patient activation: better health outcomes and care experiences; fewer data on costs. Health Aff. 32, 207-214. doi: 10.1377/hlthaff.2012.1061

Hibbard, J. H., Stockard, J., Mahoney, E. R., and Tusler, M. (2004). Development of the Patient Activation Measure (PAM): conceptualizing and measuring activation in patients and consumers. Health Serv. Res. 39, 1005-1026. doi: 10.1111/j.1475-6773.2004.00269.x
Hochhalter, A. K., Song, J., Rush, J., Sklar, L., and Stevens, A. (2010). Making the most of your healthcare intervention for older adults with multiple chronic illnesses. Patient Educ. Couns. 81, 207-213. doi: 10.1016/j.pec.2010. 01.018

Holman, H., and Lorig, K. (2004). Patient self-management: a key to effectiveness and efficiency in care of chronic disease. Public Health Rep. 119, 239-245. doi: 10.1016/j.phr.2004.04.002

Janz, N. K., and Becker, M. H. (1984). The health belief model: A decade later. Health Educ. Behav. 11, 1-47. doi: 10.1177/109019818401100101

Jordan, J. E., Briggs, A. M., Brand, C. A., and Osborne, R. H. (2008). Enhancing patient engagement in chronic disease self-management support initiatives in Australia: the need for an integrated approach. Med. J. Aust. 189(Suppl. 10), S9. Available online at: https://www.mja.com.au/system/files/issues/189_ 10_171108/jor10813_fm.pdf

Kane, R. L., and Kane, R. A. (2001). What older people want from long-term care, and how they can get it. Health Aff. 20, 114-127. doi: 10.1377/hlthaff. 20.6.114

Kersten, P., McPherson, K. M., Kayes, N. M., Theadom, A., and McCambridge, A. (2015). Bridging the goal intention-action gap in rehabilitation: a study of if-then implementation intentions in neurorehabilitation. Disabil. Rehabil. 37, 1073-1081. doi: 10.3109/09638288.2014.955137

Killaspy, H., Marston, L., Green, N., Harrison, I., Lean, M., Cook, S., et al. (2015). Clinical effectiveness of a staff training intervention in mental health inpatient rehabilitation units designed to increase patients' engagement in activities (the Rehabilitation Effectiveness for Activities for Life [REAL] study): singleblind, cluster-randomised controlled trial. Lancet Psychiatry 2, 38-48. doi: 10.1016/S2215-0366(14)00050-9

Krouse, R. S., Grant, M., McCorkle, R., Wendel, C. S., Cobb, M. D., Tallman, N. J., et al. (2016). A chronic care ostomy self-management program for cancer survivors. Psychooncology 25, 574-581. doi: 10.1002/pon.4078

Kubina, L. A., Dubouloz, C. J., Davis, C. G., Kessler, D., and Egan, M. Y. (2013). The process of re-engagement in personally valued activities during the two years following stroke. Disabil. Rehabil. 35, 236-243. doi: $10.3109 / 09638288.2012 .691936$

Lara-Cabrera, M. L., Salvesen, Ø., Nesset, M. B., De las Cuevas, C., Iversen, V. C., and Gråwe, R. W. (2016). The effect of a brief educational programme added to mental health treatment to improve patient activation: a randomized controlled trial in community mental health centres. Patient Educ. Couns. 99, 760-768. doi: 10.1016/j.pec.2015.11.028

Lazarus, R. S., and Folkman, S. (1984). Stress, Appraisal, and Coping. New York, NY: Springer Publishing Company.

Lee, K. S., Lennie, T. A., Warden, S., Jacobs-Lawson, J. M., and Moser, D. K. (2013). A comprehensive symptom diary intervention to improve outcomes in patients with HF: a pilot study. J. Card. Fail. 19, 647-654. doi: 10.1016/j.cardfail.2013.07.001

Leventhal, H. (1984). A perceptual-motor theory of emotion. Adv. Exp. Soc. Psychol. 17, 117-182. doi: 10.1016/S0065-2601(08)60119-7

Linden, A., Butterworth, S. W., and Prochaska, J. O. (2010). Motivational interviewing-based health coaching as a chronic care intervention. J. Eval. Clin. Pract. 16, 166-174. doi: 10.1111/j.1365-2753.2009.01300.x

Lutz, W., Sanderson, W., and Scherbov, S. (2008). The coming acceleration of global population ageing. Nature 451, 716-719. doi: 10.1038/nature06516

Maclachlan, E. W., Shepard-Perry, M. G., Ingo, P., Uusiku, J., Mushimba, R., Simwanza, R., et al. (2016). Evaluating the effectiveness of patient education and empowerment to improve patient-provider interactions in antiretroviral therapy clinics in Namibia. AIDS Care. 28, 620-627. doi: 10.1080/09540121.2015.1124975

Maindal, H. T., Sandbæk, A., Kirkevold, M., and Lauritzen, T. (2011). Effect on motivation, perceived competence, and activation after participation in the "Ready to Act" programme for people with screen-detected dysglycaemia: A 1-year randomised controlled trial, Addition-DK. Scand. J. Public Health 39, 262-271. doi: 10.1177/1403494811402721

Maranda, M. J., Deen, D., Elshafey, S., Herrera, M., and Gold, M. R. (2014). Response to a patient activation intervention among Spanish-speaking patients at a community health center in New York City. J. Health Care Poor Underserved 25, 591-604. doi: 10.1353/hpu.2014.0110

Mosen, D. M., Schmittdiel, J., Hibbard, J., Sobel, D., Remmers, C., and Bellows, J. (2007). Is patient activation associated with outcomes of care for adults with 
chronic conditions?. J. Ambul. Care Manage. 30, 21-29. doi: 10.1097/00004479200701000-00005

Nagykaldi, Z., Aspy, C. B., Chou, A., and Mold, J. W. (2012). Impact of a Wellness Portal on the delivery of patient-centered preventive care. J. Am. Board Fam. Pract. 25, 158-167. doi: 10.3122/jabfm.2012.02.110130

O’Leary, K. J., Lohman, M. E., Culver, E., Killarney, A., Smith, G. R., and Liebovitz, D. M. (2015). The effect of tablet computers with a mobile patient portal application on hospitalized patients' knowledge and activation. J. Am. Med. Inform. Assoc. 23, 159-165. doi: 10.1093/jamia/ocv058

Pennebaker, J. W., and Beall, S. K. (1986). Confronting a traumatic event: toward an understanding of inhibition and disease. J. Abnorm. Psychol. 95, 274.

Prochaska, J. O., and DiClemente, C. C. (1986). "Toward a comprehensive model of change," in Treating Addictive Behaviors, eds W. R. Miller and N. Heather (New York, NY: Springer), 3-27.

Remmers, C., Hibbard, J., Mosen, D. M., Wagenfield, M., Hoye, R. E., and Jones, C. (2009). Is patient activation associated with future health outcomes and healthcare utilization among patients with diabetes?. J. Ambul. Care Manage. 32, 320-327. doi: 10.1097/JAC.0b013e3181ba6e77

Riegel, B., Dickson, V. V., Hoke, L., McMahon, J. P., Reis, B. F., and Sayers, S. (2006). A motivational counseling approach to improving heart failure self-care: mechanisms of effectiveness. J. Cardiovas. Nurs. 21, 232-241. doi: 10.1097/00005082-200605000-00012

Rise, M. B., Eriksen, L., Grimstad, H., and Steinsbekk, A. (2016). The long-term effect on mental health symptoms and patient activation of using patient feedback scales in mental health out-patient treatment. A randomised controlled trial. Patient Educ. Couns. 99, 164-168. doi: 10.1016/j.pec.2015.07.016

Rosenberg, H. J., Rosenberg, S. D., Ernstoff, M. S., Wolford, G. L., Amdur, R. J., Elshamy, M. R., et al. (2002). Expressive disclosure and health outcomes in a prostate cancer population. Int. J. Psychiatry Med. 32, 37-53. doi: 10.2190/AGPF-VB1G-U82E-AE8C

Schueller, S. M., and Parks, A. C. (2012). Disseminating self-help: positive psychology exercises in an online trial. J. Med. Intern. Res. 14:e63. doi: 10.2196/jmir. 1850

Seligman, M. E., and Csikszentmihalyi, M. (2014). Positive Psychology: An Introduction. Netherlands: Springer.

Seligman, M. E., Steen, T. A., Park, N., and Peterson, C. (2005). Positive psychology progress: empirical validation of interventions. Am. Psychol. 60:410. doi: 10.1037/0003-066X.60.5.410

Shah, V. O., Carroll, C., Mals, R., Ghahate, D., Bobelu, J., Sandy, P., et al. (2015). A home-based educational intervention improves patient activation measures and diabetes health indicators among zuni indians. PLoS ONE 10:e0125820. doi: 10.1371/journal.pone.0125820

Shearer, N. B. C., Fleury, J. D., and Reed, P. G. (2009). The rhythm of health in older women with chronic illness. Res. Theory Nurs. Pract. 23, 148-160. doi: 10.1891/1541-6577.23.2.148
Shively, M. J., Gardetto, N. J., Kodiath, M. F., Kelly, A., Smith, T. L., and Stepnowsky, C. (2013). Effect of patient activation on selfmanagement in patients with heart failure. J. Cardiovas. Nurs. 28, 20-34. doi: 10.1097/JCN.0b013e318239f9f9

Shively, M., Kodiath, M., Smith, T. L., Kelly, A., Bone, P., and Fetterly, L. (2005). Effect of behavioral management on quality of life in mild heart failure: a randomized controlled trial. Patient Educ. Couns. 58, 27-34. doi: 10.1016/j.pec.2004.06.007

Simmons, L. A., Wolever, R. Q., Bechard, E. M., and Snyderman, R. (2014). Patient engagement as a risk factor in personalized health care: a systematic review of the literature on chronic disease. Genome Med. 6, 1-16. doi: 10.1186/gm533. eCollection 2014

Sin, N. L., and Lyubomirsky, S. (2009). Enhancing well-being and alleviating depressive symptoms with positive psychology interventions: a practicefriendly meta-analysis. J. Clin. Psychol. 65, 467-487. doi: 10.1002/jclp. 20593

Tan, K. K., Chan, S. W. C., Wang, W., and Vehviläinen-Julkunen, K. (2016). A salutogenic program to enhance sense of coherence and quality of life for older people in the community: a feasibility randomized controlled trial and process evaluation. Patient Educ. Couns. 99, 108-116. doi: 10.1016/j.pec.2015.08.003

Thomson, R., Murtagh, M., and Khaw, F. M. (2005). Tensions in public health policy: patient engagement, evidence-based public health and health inequalities. Qual. Saf. Health Care 14, 398-400. doi: 10.1136/qshc.2005. 014175

Weil, A. R. (2016). The patient engagement imperative. Health Aff. 35, 563-563. doi: $10.1377 /$ hlthaff.2016.0337

Wellard, S. J., and Street, A. F. (1999). Family issues in home-based care. Int. J. Nurs. Pract. 5, 132-136. doi: 10.1046/j.1440-172x.1999.00163.x

Wetzels, R., Harmsen, M., Van Weel, C., Grol, R., and Wensing, M. (2007). Interventions for improving older patients' involvement in primary care episodes. Cochrane Database Syst. Rev. 1:CD004273. doi: 10.1002/14651858.cd004273.pub2

Wolff, J. L., Starfield, B., and Anderson, G. (2002). Prevalence, expenditures, and complications of multiple chronic conditions in the elderly. Arch. Int. Med. 162, 2269-2276. doi: 10.1001/archinte.162.20.2269

Conflict of Interest Statement: The authors declare that the research was conducted in the absence of any commercial or financial relationships that could be construed as a potential conflict of interest.

Copyright $(0) 2016$ Menichetti and Graffigna. This is an open-access article distributed under the terms of the Creative Commons Attribution License (CC BY). The use, distribution or reproduction in other forums is permitted, provided the original author(s) or licensor are credited and that the original publication in this journal is cited, in accordance with accepted academic practice. No use, distribution or reproduction is permitted which does not comply with these terms. 